\title{
Reprogramming macrophages to an anti-inflammatory phenotype by helminth antigens reduces murine atherosclerosis
}

Citation for published version (APA):

Wolfs, I. M. J., Stoger, J. L., Goossens, P., Pottgens, C., Gijbels, M. J. J., Wijnands, E., van der Vorst, E. P. C., van Gorp, P., Beckers, L., Engel, D., Biessen, E. A. L., Kraal, G., van Die, I., Donners, M. M. P. C., \& de Winther, M. P. J. (2014). Reprogramming macrophages to an anti-inflammatory phenotype by helminth antigens reduces murine atherosclerosis. Faseb Journal, 28(1), 288-299.

https://doi.org/10.1096/fj.13-235911

Document status and date:

Published: 01/01/2014

DOI:

10.1096/fj.13-235911

Document Version:

Publisher's PDF, also known as Version of record

\section{Document license:}

Taverne

Please check the document version of this publication:

- A submitted manuscript is the version of the article upon submission and before peer-review. There can be important differences between the submitted version and the official published version of record.

People interested in the research are advised to contact the author for the final version of the publication, or visit the DOI to the publisher's website.

- The final author version and the galley proof are versions of the publication after peer review.

- The final published version features the final layout of the paper including the volume, issue and page numbers.

Link to publication

\footnotetext{
General rights rights.

- You may freely distribute the URL identifying the publication in the public portal. please follow below link for the End User Agreement:

www.umlib.nl/taverne-license

Take down policy

If you believe that this document breaches copyright please contact us at:

repository@maastrichtuniversity.nl

providing details and we will investigate your claim.
}

Copyright and moral rights for the publications made accessible in the public portal are retained by the authors and/or other copyright owners and it is a condition of accessing publications that users recognise and abide by the legal requirements associated with these

- Users may download and print one copy of any publication from the public portal for the purpose of private study or research.

- You may not further distribute the material or use it for any profit-making activity or commercial gain

If the publication is distributed under the terms of Article $25 f a$ of the Dutch Copyright Act, indicated by the "Taverne" license above, 


\title{
Reprogramming macrophages to an anti-inflammatory phenotype by helminth antigens reduces murine atherosclerosis
}

\author{
Ine M. J. Wolfs, ${ }^{* \dagger}$ J. Lauran Stöger, ${ }^{*}, \S$ Pieter Goossens, ${ }^{*}, \|$ Chantal Pöttgens, ${ }^{*},+$ \\ Marion J. J. Gijbels, ${ }^{*},+, \S$ Erwin Wijnands, ${ }^{\dagger}$ Emiel P. C. van der Vorst, ${ }^{*}$ \\ Patrick van Gorp, ${ }^{*}$ Linda Beckers, ${ }^{\dagger, \S}$ David Engel, ${ }^{\dagger}$ Erik A. L. Biessen, ${ }^{\dagger}$ Georg Kraal, ${ }^{\mathrm{I}}$ \\ Irma van Die, ${ }^{\text {I }}$ Marjo M. P. C. Donners, ${ }^{*},{ }^{\dagger}$ and Menno P. J. de Winther ${ }^{*, \S, 1}$ \\ *Department of Molecular Genetics, ${ }^{\dagger}$ Department of Pathology, and ${ }^{\ddagger}$ Department of Physiology, \\ Cardiovascular Research Institute Maastricht (CARIM), Maastricht University, Maastricht, The \\ Netherlands; ${ }^{\circledR}$ Department of Medical Biochemistry, Academic Medical Center (AMC), University of \\ Amsterdam, Amsterdam, The Netherlands; "Centre d'Immunologie de Marseille-Luminy (CIML), \\ Aix-Marseille University, Marseille, France; and ${ }^{\mathbb{I}}$ Department of Molecular Cell Biology and \\ Immunology, Vrije Universiteit (VU) Medical Center Amsterdam, Amsterdam, The Netherlands
}

\begin{abstract}
Atherosclerosis is a lipid-driven inflammatory disease of the vessel wall, characterized by the chronic activation of macrophages. We investigated whether the helminth-derived antigens [soluble egg antigens (SEAs)] could modulate macrophage inflammatory responses and protect against atherosclerosis in mice. In bone marrow-derived macrophages, SEAs induce anti-inflammatory macrophages, typified by high levels of IL-10 and reduced secretion of proinflamma-

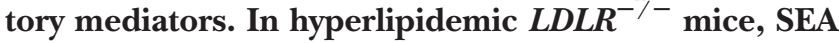
treatment reduced plaque size by $44 \%$, and plaques were less advanced compared with PBS-injected littermate controls. The atheroprotective effect of SEAs was found to be mainly independent of cholesterol lowering and T-lymphocyte responses but instead could be attributed to diminished myeloid cell activation. SEAs reduced circulating neutrophils and inflammatory Ly6 $\mathrm{C}^{\text {high }}$ monocytes, and macrophages showed high IL-10 production. In line with the observed systemic effects, atherosclerotic lesions of SEA-treated mice showed reduced intraplaque inflammation as inflammatory markers [TNF- $\alpha$, monocyte chemotactic protein 1 (MCP-1), intercellular adhesion molecule-1 (ICAM-1), vascular cell adhesion molecule-1 (VCAM-1), and CD68], neutrophil content, and newly recruited macro-
\end{abstract}

Abbreviations: AAM, alternatively activated macrophage; ARBP, acidic ribosomal phosphoprotein; Arg-1, arginase 1; BMDM, bone marrow derived macrophage; DC, dendritic cell; EAE, experimental autoimmune encephalomyelitis; EC, endothelial cell; HCD, high-cholesterol diet; IBD, inflammatory bowel disease; ICAM-1, intercellular adhesion molecule-1; IL, interleukin; iNOS, inducible nitric oxide synthase; LPS, lipopolysaccharide; MCP-1, monocyte chemotactic protein 1; MMR, macrophage mannose receptor; PBS, phosphate-buffered saline; s.c., subcutaneously; SEA, soluble egg antigen; TLR, Toll-like receptor; TNF $\alpha$, tumor necrosis factor $\alpha ; \mathrm{T}_{\text {reg }}$, regulatory $\mathrm{T}$; VCAM-1, vascular cell adhesion molecule-1; Ym-1, chitinase 3-like 3 phages were decreased. We show that SEA treatment protects against atherosclerosis development by dampening inflammatory responses. In the future, helminthderived components may provide novel opportunities to treat chronic inflammatory diseases, as they diminish systemic inflammation and reduce the activation of immune cells.-Wolfs, I. M. J., Stöger, J. L., Goossens, P., Pöttgens, C., Gijbels, M. J. J., Wijnands, E., van der Vorst, E. P. C., van Gorp, P., Beckers, L., Engel, D., Biessen, E. A. L., Kraal, G., van Die, I., Donners, M. M. P. C., de Winther, M. P. J. Reprogramming macrophages to an anti-inflammatory phenotype by helminth antigens reduces murine atherosclerosis. FASEB J. 28, 288-299 (2014). www.fasebj.org

Key Words: immune modulation $\cdot$ monocytes $\cdot$ inflammation $\cdot$ schistosome $\cdot$ mouse

ATHEROSCLERosis IS THE MAIN underlying pathology of cardiovascular events like stroke and myocardial infarction, which form the leading cause of death worldwide. This chronic disease of the vessel wall is characterized by local lipid deposits and sustained inflammatory responses. In atherosclerosis, macrophages have been shown to be critical players at all stages. During plaque initiation, monocytes are attracted to the vessel wall and differentiate into macrophages that engulf the modified lipids and become foam cells. On further lesion progression, more macrophages accumulate and attract leukocytes to the plaque, thereby aggravating

\footnotetext{
${ }^{1}$ Correspondence: Department of Medical Biochemistry, Rm. L01-146.2, Academic Medical Center, University of Amsterdam, Meibergdreef 9, 1105 AZ Amsterdam, The Netherlands. E-mail: m.dewinther@amc.uva.nl

doi: 10.1096/fj.13-235911

This article includes supplemental data. Please visit http:// www.fasebj.org to obtain this information.
} 
intraplaque inflammation and contributing to lesion growth and instability. Eventually, plaques may rupture due to matrix degradation by macrophages, thereby exposing prothrombotic material in the blood, causing thrombus formation (1).

Macrophages are cells of the innate immune system that play a central role in tissue homeostasis, orchestration of inflammation, and host defense against pathogens (2). Depending on their microenvironment, they show plasticity with great phenotypical and functional diversity. A generally used nomenclature to distinguish macrophage subsets based on their activation status is the M1 and M2 paradigm (3). Classically activated macrophages (CAMs; M1) are typically generated by proinflammatory factors like interferon $\gamma($ IFN- $\gamma$ ) or Toll-like receptor (TLR) activation and secrete inflammatory cytokines [e.g., interleukin $1 \beta$ (IL-1 $\beta$ ), IL-12, and tumor necrosis factor $\alpha(\mathrm{TNF}-\alpha)]$ and chemokines promoting inflammatory responses. On the other hand, alternatively activated macrophages (AAMs), sometimes referred to as M2a, are induced by IL- 4 or IL-13 and provide signals for tissue repair, fibrosis, and wound healing. Regulatory macrophages (M2c) have a deactivating anti-inflammatory capacity and are induced by IL-10, transforming growth factor- $\beta$ (TGF- $\beta$ ), or glucocorticoids. These latter two M2 subsets are characterized by secretion of high levels of the anti-inflammatory cytokine IL-10. Regarding atherosclerosis, both M1 and M2 macrophages have been identified in human and murine atherosclerotic lesions (4-6), and we recently showed that the rupture-prone shoulder regions of human atherosclerotic plaques are dominated by M1 macrophages (7). Since inflammatory mechanisms are major contributors to plaque initiation, development, and vulnerability, reprogramming the activation status of macrophages to decrease the high inflammatory burden may have therapeutic potential to fight complications of atherosclerosis (8).

Over the past decade, there has been great interest in the inverse global prevalence of chronic autoimmune diseases and helminth infection, linked to the so called hygiene hypothesis (9). Helminths are eukaryotic parasitic worms that strongly modulate immune responses in their hosts by induction of $\mathrm{T}_{\mathrm{H}} 2$ and regulatory $\mathrm{T}$ $\left(\mathrm{T}_{\text {reg }}\right)$ cells, anti-inflammatory cytokines, and AAMs (M2a; ref. 10). During helminth infection, the IL-4induced AAMs are necessary to ensure host survival via down-regulation of $\mathrm{T}_{\mathrm{H}} 1$ inflammatory responses that are initiated by the schistosome eggs $(11,12)$. It has been shown that helminths can be used to protect against hyperinflammation seen in $\mathrm{T}_{\mathrm{H}} 1$-driven autoimmune disorders $(9,13)$. In animal models, infection with live helminths or their eggs was beneficial in experimental autoimmune encephalomyelitis (EAE; ref. 14), type I diabetes (15), and colitis (16). At present, the first results of small-scale human trials show that infection with the pig whipworm Trichuris suis beneficially improves remission in patients with inflammatory bowel disease (IBD; refs. 17-19) and multiple sclerosis (MS; ref. 20, 21). However, as some live parasitic worms may also cause detrimental side-effects in their host, parasite-derived immune-modulating components are potentially more suitable for therapeutic use. In this aspect, several helminth-derived antigens have already been shown to decrease disease progression of MS $(22,23)$ and diabetes type I (24) in mice. Their efficacy in treating cardiovascular diseases, however, has not been investigated so far. In this study, we assessed the effect of Schistosoma mansoni-derived soluble egg antigens (SEAs) on macrophage function and atherosclerosis development. SEAs are widely used antigenic preparations from the crude extract of mature schistosome eggs and contain a broad array of components, such as proteins, glycoproteins, polysaccharides, and glycolipids, that exert $\mathrm{T}_{\mathrm{H}} 2$ - and M2a-driven immune responses in vitro and in vivo (25).

\section{MATERIALS AND METHODS}

\section{Mice}

C57BL/6 wild-type and $L D L R^{-/-}$mice (on a C57BL/6 background) were obtained from the animal breeding facility at Maastricht University (Maastricht, The Netherlands). All animal experiments were executed following the institutional guidelines and were approved by the Ethical Committee for Animal Welfare of the Maastricht University (permit 2008082).

\section{SEAs}

S. mansoni SEAs, solubilized in endotoxin-free phosphatebuffered saline (PBS), were kindly provided by Fred Lewis (Biomedical Research Institute, Rockville MD, USA) and prepared as described previously (26). Briefly, SEAs were prepared from homogenized eggs isolated from livers of $S$. mansoni-infected mice. After ultracentrifugation of the crude SEAs $\left(100,000 \mathrm{~g}\right.$ for $90 \mathrm{~min}$ at $\left.4^{\circ} \mathrm{C}\right)$, the supernatant containing the SEAs was passed through a sterile $0.2-\mu \mathrm{m}$ filter. Protein concentration of SEAs was determined using the Bradford method. SEAs alone did not induce dendritic cell (DC) maturation, nor did they induce macrophage NF-кB activation or cytokine secretion (data not shown), and they were thus assumed to be endotoxin-free.

\section{SEA treatment in $L D L R^{-/-}$mice}

In all animal experiments, the injection dose of SEAs per mouse was determined as reported previously by others (23, 24, 27, 28). As SEAs are dissolved in sterile endotoxin-free PBS, littermate control mice received injection with sterile endotoxin-free PBS only. To investigate the immune modulatory effect of SEAs in vivo, $L D L R^{-/-}$mice fed a highcholesterol diet (HCD; $16 \%$ fat, $0.15 \%$ cholesterol; AB Diets, Woerden, The Netherlands) were weekly injected subcutaneously (s.c.) for $5 \mathrm{wk}$ with $50 \mu \mathrm{g}$ SEAs or control treatment ( $n=20$ /group). To study atherosclerosis, $L D L R^{-/-}$mice were injected s.c. twice (d 0 and 7) with $50 \mu \mathrm{g}$ SEAs or control treatment before the animals were fed an HCD for another 10 wk, whereupon the mice were euthanized ( $n=20 /$ group). During the HCD period, mice received $50 \mu \mathrm{g}$ SEAs or control treatment s.c. weekly. Before the start of experiment, as well as at 0,5 , and $10 \mathrm{wk}$ of HCD, body weight was determined, and blood was collected for further analysis. 


\section{Atherosclerotic plaque quantification and scoring}

Upon euthanasia, hearts were taken out, cut perpendicular to the heart axis just below the atrial tips, and frozen in Tissue-Tec (Shandon, Veldhoven, The Netherlands). The aortic root was cut into sections of $7 \mu \mathrm{m}$, and serial crosssections from every $42 \mu \mathrm{m}$ were stained with toluidin blue. Lesion areas, as well as necrosis, were quantified on toluidinstained sections using Adobe Photoshop software (Adobe Systems, San Jose, CA, USA). Moreover, plaques were phenotypically scored into early, moderate, or advanced. Early plaques consisted mainly of macrophage-derived foam cells, while moderate lesions also contained a protective fibrous cap. Advanced lesions showed signs of media infiltration and adventitial influx. Finally, lesions were pathologically examined for composition, i.e., collagen content, necrosis, foam cell content, and amount of inflammatory cells.

\section{Flow cytometry}

Blood was collected, subjected to erylysis, and stained with antibodies to distinguish leukocyte subsets. Absolute numbers of circulating leukocytes were determined by flow cytometry in combination with BD Trucount Beads (BD Biosciences, San Jose, CA, USA). Leukocytes are described as CD45 ${ }^{+}$, T cells as $\mathrm{CD}_{4} 5^{+} \mathrm{CD}^{+}{ }^{+} \mathrm{NK} 1.1^{-}$, NK cells as $\mathrm{CD}^{-} 5^{+} \mathrm{CD}^{-}$ $\mathrm{NK} 1.1^{+}$, B cells as CD45 ${ }^{+} \mathrm{CD}^{-}{ }^{-} \mathrm{NK} 1.1^{-} \mathrm{B} 220^{+}$, granulocytes as $\mathrm{CD} 45^{+} \mathrm{CD}^{-} \mathrm{NK}^{-} 1^{-} \mathrm{B}^{-} 20^{-} \mathrm{CD} 11 \mathrm{~b}^{+} \mathrm{Ly}^{+} \mathrm{G}^{+}$, and monocytes as CD $45^{+} \mathrm{CD}^{-} \mathrm{NK}^{-} 1^{-} \mathrm{B}_{220^{-}} \mathrm{CD} 11 \mathrm{~b}^{+} \mathrm{Ly}^{-} \mathrm{G}^{-}$. Inflammatory and resident monocytes were divided as being Ly6C $\mathrm{C}^{\text {high }}$ and $\mathrm{Ly}_{6 \mathrm{C}}{ }^{-}$respectively. T-helper cells were defined as $\mathrm{CD} 45^{+} \mathrm{CD}^{+} \mathrm{CD}^{+}$, cytotoxic $\mathrm{T}$ cells CD $45^{+} \mathrm{CD}^{+} \mathrm{CD}^{+}$, and $\mathrm{T}_{\text {reg }}$ cells $\mathrm{CD}^{+} \mathrm{CD}^{+} \mathrm{CD}^{+} 5^{+}$Foxp3 $^{+}$.

IL-10 and IL-12 production by peritoneal macrophages was assessed after $6 \mathrm{~h}$ in vitro activation by $10 \mathrm{ng} / \mathrm{ml}$ lipopolysaccharide (LPS) in presence of GolgiSTOP (1:2000; BD Biosciences). Cytokine production in peritoneal cells was determined in macrophages as identified in the $\mathrm{CD} 19^{-} \mathrm{F} 4 / 80^{+}$ cell population.

All samples were measured on a FACS Canto II (BD Biosciences). Antibodies applied are listed in Supplemental Table S1.

\section{Macrophage culture}

Bone marrow-derived macrophages (BMDMs) were cultured as described previously (29). Briefly, bone marrow cells were isolated from femurs and tibiae of $\mathrm{C} 57 \mathrm{BL} / 6$ mice and cultured in RPMI 1640 (Life Technologies, Bleiswijk, The Netherlands) with $10 \%$ heat-inactivated fetal calf serum (Bodinco B.V., Alkmaar, The Netherlands), penicillin (100 U/ml), streptomycin $(100 \mu \mathrm{g} / \mathrm{ml})$, and L-glutamine (2 mM; Gibco; Invitrogen, Breda, The Netherlands; R10) supplemented with 15\% L929-conditioned medium (LCM) for 8-9 d to generate BMDMs. BMDMs were primed with $50 \mu \mathrm{g} / \mathrm{ml}$ SEAs for $24 \mathrm{~h}$. BMDMs primed with $20 \mathrm{ng} / \mathrm{ml}$ recombinant mouse IL-4 (Peprotech, London, UK) were used as positive controls for M2a macrophages. Subsequently, BMDMs were activated with $10 \mathrm{ng} / \mathrm{ml}$ LPS for 3,8 , or $24 \mathrm{~h}$. All data are representative of $\geq 3$ independent experiments, each time using triplicate wells for every condition.

Resident peritoneal macrophages were obtained by flushing the peritoneal cavity with $10 \mathrm{ml}$ ice-cold sterile PBS, followed by subsequent overnight adherence of macrophages to plastic culture plates in RPMI 1640 medium (Life Technologies) with $10 \%$ heat-inactivated fetal calf serum (Bodinco B.V.), penicillin $(100 \mathrm{U} / \mathrm{ml})$, streptomycin $(100 \mu \mathrm{g} / \mathrm{ml})$, and $2 \mathrm{mM}$ L-glutamine (Gibco; Invitrogen; R10). After overnight culture, nonadherent cells were removed, and the remaining cells were restimulated with $50 \mu \mathrm{g} / \mathrm{ml}$ SEAs or $10 \mathrm{ng} / \mathrm{ml} \mathrm{LPS}$ for $24 \mathrm{~h}$.

\section{Immunohistochemical staining}

Cryosections of the aortic root were fixed in acetone, followed by incubation with antibodies against granulocytes (NIMP, directed against Ly6G; a gift from P. Heeringa; University Medical Center Groningen, Groningen, The Netherlands) and newly recruited macrophages (ERMP-58; a gift from P. Leenen; Erasmus University Medical Center, Rotterdam, The Netherlands), followed by detection with a biotin-labeled rabbit anti-rat antibody and staining with the ABC kit (Vector Laboratories, Burlingame, CA, USA).

\section{Cholesterol and triglyceride measurements}

For size fractionation of lipoproteins, $60 \mu \mathrm{l}$ of pooled plasma (3 pools of 3 mice/group) was separated using an AKTA Basic Chromotography System with a Superose 6PC 3.2/30 column (Amersham Biosciences, Roosendaal, The Netherlands). Total plasma cholesterol and triglyceride levels, as well as cholesterol in lipoprotein fractions, were determined using standard enzymatic kits according to manufacturer's protocols (Sigma-Aldrich, Zwijndrecht, The Netherlands).

\section{Quantitative PCR (qPCR)}

mRNA was isolated from BMDMs, peritoneal macrophages, or splenocytes with the High Pure RNA Isolation Kit (Roche, Woerden, The Netherlands) and from the aortic arch with the Qiagen RNeasy mini column kit (Qiagen, Venlo, The Netherlands) respectively. Total mRNA (500 ng) was reverse transcribed using the iScript cDNA Synthesis Kit (Bio-Rad, Veenendaal, The Netherlands). Quantitative PCR (qPCR) was performed using $10 \mathrm{ng}$ cDNA, $300 \mathrm{nM}$ of each primer, and sensiMix SYBR Hi-ROX (Bioline, Brussels, Belgium) in a total volume of $20 \mu \mathrm{l}$. Gene expression levels were relatively expressed and corrected for housekeeping genes acidic ribosomal phosphoprotein (ARBP) and cyclophilin. Primer sequences were as follows: TNF- $\alpha$, Fw 5 -CATCTTCTCAAAATTCGAGTGACAA-3' and Rv 5'-TGGGAGTAGACAAGGTACAACCC 3'; IL-10, Fw 5'-GCTCTTACTGACTGGCATGAG-3' and Rv 5'-CGCAGCTCTAGGAGCATGTG-3'; IL-12, Fw 5'-GGTGCAAAGAAACATGGACTTG-3' and Rv 5'-CACATGTCACTGCCCGAGAGT-3'; inducible nitric oxide synthase (iNOS), Fw 5' -TTGCAAGCTGATGGTCAAGATC-3' and Rv 5' CAACCCGAGCTCCTGGAA-3'; CD68, Fw 5'-TGACCTGCTCTCTCTAAGGCTACA-3' and Rv 5'-TCACGGTTGCAAGAGAAACATG$3^{\prime}$; vascular cell adhesion molecule-1 (VCAM-1), $\mathrm{FW}_{\mathrm{W}}$ 5'-GTGTTGAGCTCTGTGGGTTTTG-3' and Rv 5'TTAATTACTGGATCTTCAGGGAATGAG-3'; intercellular adhesion molecule-1 (ICAM-1), Fw 5'-CTACCATCACCGTGTATTCGTTTC-3' and Rv 5'-CGGTGCTCCACCATCCA-3'; cyclophilin Fw, 5'-TTCCTCCTTTCACAGAATTATTCCA-3' and Rv 5'-CCGCCAGTGCCATTATGG-3'; macrophage mannose receptor (MMR), Fw 5'-CAACTCACTCAAGATTGTCAGCAA-3' and Rv 5'-TGGCAGTGATGGCATGGA-3'; arginase 1 (Arg-1), Fw 5' CATGGGCAACCTGTGTCCTT- $3^{\prime}$ and Rv $5^{\prime}$-CGATGTCTTTGGCAGATATGCA-3'; Fizz-1, Fw 5'-CTGCCCTGCTGGGATGAC-3' and Rv 5'-TCCACTCTGGATCTCCCAAGA-3'; chitinase 3-like 3 (Ym-1), Fw 5'TGGCCCACCAGGAAAGTACA-3' and Rv 5'AGTGGCTCCTTCATTCAGAAA-3'; ARBP, Fw 5'-GGACCCGAGAAGACCTCCTT-3' and Rv 5'-GCACATCACTCAGAATTTCAATGG-3'. 


\section{ELISA and NO assay}

LPS-induced IL-10, IL-12p40, and TNF- $\alpha$ secretion was measured in the supernatant of the BMDM culture with ELISA (Invitrogen) according to the manufacturer's protocol. To determine the activity of iNOS, $\mathrm{NO}_{2}{ }^{-}$concentrations were determined in the cellular medium using Griess reagent and measured at $540 \mathrm{~nm}$ (Benchmark microplate reader; Bio$\mathrm{Rad})$.

\section{Adhesion assay}

Macrophage adhesion assay was performed as described previously (29). Briefly, a confluent monolayer of bEND5 endothelial cells (ECs) was grown in fluorescence 96-well microplates (Greiner Bio-one, Frickenhausen, Germany). ECs were activated with $40 \mathrm{ng} / \mathrm{ml} \mathrm{TNF}-\alpha$ for $4 \mathrm{~h}$ before the adhesion experiment. BMDMs were primed with or without $50 \mu \mathrm{g} / \mathrm{ml} \mathrm{SEAs} \mathrm{for} 24 \mathrm{~h}$, whereupon macrophages were collected and fluorescently labeled with a PKH67 dye according to the manufacturer's instructions (Sigma-Aldrich). After the ECs and BMDMs were incubated for $30 \mathrm{~min}$, the wells were washed 3 times with R10, and the adherence of BMDMs was measured by fluorometry in a Synergy HT microtiter plate reader (BioTek, Bad Friedrichshall, Germany) at an excitation of $485 \mathrm{~nm}$ and emission of $520 \mathrm{~nm}$. Data are representative of 3 independent experiments; in each experiment, 5 wells for all conditions were included.

\section{Statistics}

All statistical analyses were performed using Graphpad Prism (GraphPad Software, Inc., San Diego, CA, USA). The statistical significance of differences was evaluated with Student's $t$ test unless otherwise indicated. Data are presented as means $\pm \mathrm{SE}$. Significance was accepted at the level of $P<0.05$. All mouse data passed a normality test.

\section{RESULTS}

\section{SEAs induce anti-inflammatory macrophages}

To study the effect of SEAs on the macrophage phenotype, we examined M1 and M2 polarization features after SEA vs. control treatment, followed by subsequent LPS activation in BMDMs in vitro. BMDMs treated with
SEAs showed a decreased secretion of the proinflammatory factors IL-12, TNF- $\alpha$, and $\mathrm{NO}_{2}{ }^{-}$after LPS activation (Fig. $1 A-C$ ). On the other hand, SEA pretreatment increased the production of the anti-inflammatory cytokine IL-10 on LPS activation (Fig. 1D). As helminth infection is characterized by a marked induction of alternatively activated M2a macrophages via IL-4R $\alpha$ signaling (30), we compared the expression of acknowledged M2a genes in SEA- vs. IL-4-primed macrophages. In contrast to IL-4 priming, which upregulated the M2a genes Arg-1, MMR, and Ym-1, SEAtreatment did not result in an induction of these genes (Supplemental Fig. S1A-C). Thus, SEA treatment induces macrophages with anti-inflammatory properties in vitro that are distinct from alternatively activated M2a macrophages.

To investigate whether SEAs also yield anti-inflammatory macrophages under hyperlipidemic conditions in vivo, $L D L R^{-/-}$mice fed an HCD were treated weekly with $50 \mu \mathrm{g}$ SEAs or PBS for $5 \mathrm{wk}$ (short-term treatment). During the experiment, mice did not display any health problems, and food intake and body weight were equal between control and SEA-injected mice. SEA-treated mice did not display any health concerns, and no signs of inflammation or other abnormalities were found in the organs after pathological examination on death. Since a key characteristic of schistosome infection is the induction of $\mathrm{T}_{\mathrm{H}} 2 \mathrm{~T}$ lymphocytes, the T-cell polarization status was determined as proof of principle. Relative numbers of circulating $\mathrm{T}$ cells were unaffected (Fig. 2A), and we found a slight, although significant, induction of $\mathrm{T}_{\mathrm{H}}$ 2-related genes in SEAinjected compared with PBS-injected mice, while $\mathrm{T}_{\mathrm{H}} 1$ and $\mathrm{T}_{\text {reg }}$ genes were unaffected (Fig. $2 B$ ). In line with our in vitro findings, peritoneal macrophages isolated from SEA-treated mice displayed an anti-inflammatory phenotype, as expression of LPS-induced IL-12 and iNOS (Fig. 2C,D) was decreased and IL-10 (Fig. 2F) was enhanced. Interestingly, IL-10 expression was significantly augmented under nonactivated conditions in macrophages from SEA-treated mice and even showed an increase after restimulation with SEAs ex vivo. Again, we did not find an up-regulation of alternative M2a
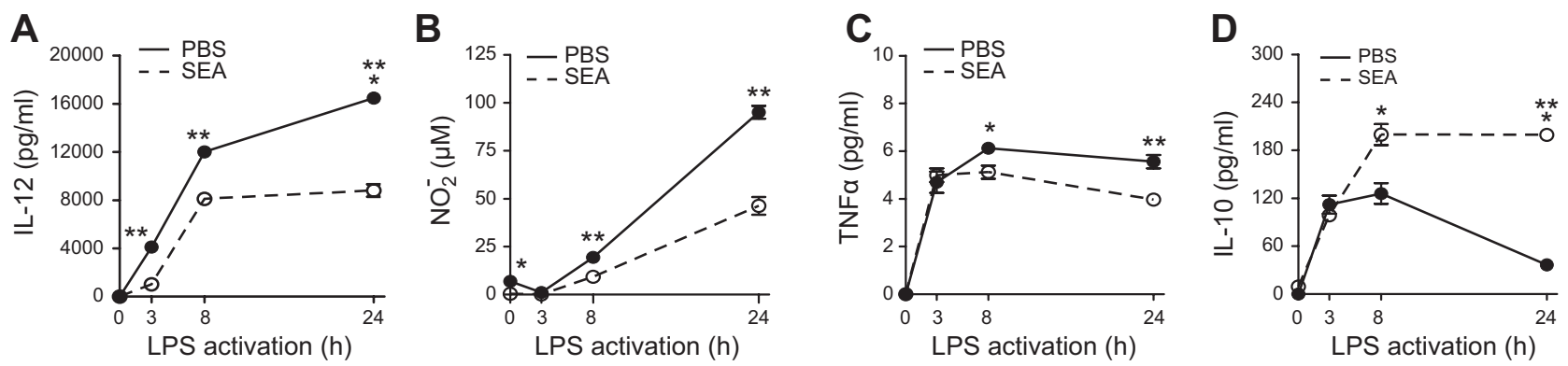

Figure 1. SEAs induce anti-inflammatory macrophages in vitro. BMDMs were either left untreated (black lines) or primed with $50 \mu \mathrm{g} / \mathrm{ml}$ SEAs (dotted lines) for $24 \mathrm{~h}$, whereupon the cells were activated by $10 \mathrm{ng} / \mathrm{ml} \mathrm{LPS} \mathrm{for} 0$, 3, 8, or $24 \mathrm{~h}$ respectively. $A-C)$ Secretion of the proinflammatory M1 factors IL-12 $(A), \mathrm{NO}_{2}{ }^{-}(B)$, and TNF- $\alpha(C)$ was reduced by SEA priming, as measured in the cellular supernatant by ELISA or NO assay. D) Secretion of the anti-inflammatory M2 cytokine IL-10 was enhanced by SEA priming, as measured by ELISA. Data represent means \pm SEM of triplicate wells of $\geq 3$ independent experiments. $* P<0.05, * * P<0.01$. 

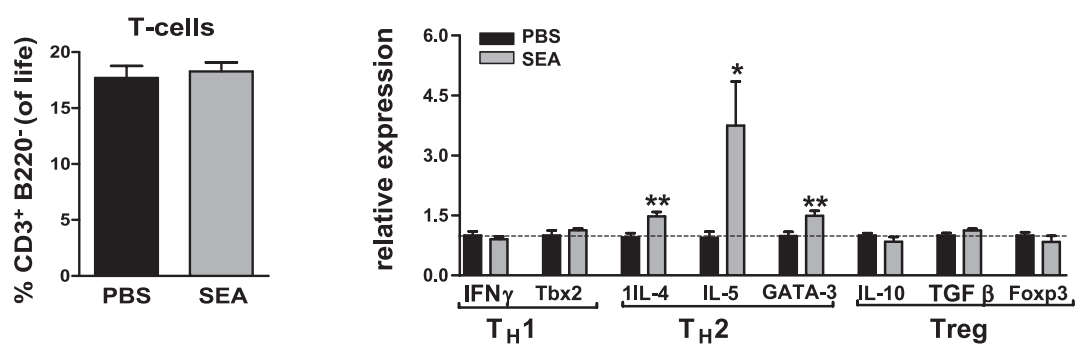

C

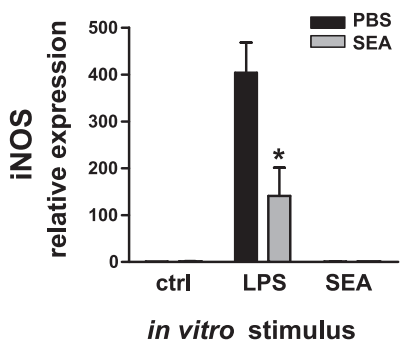

D

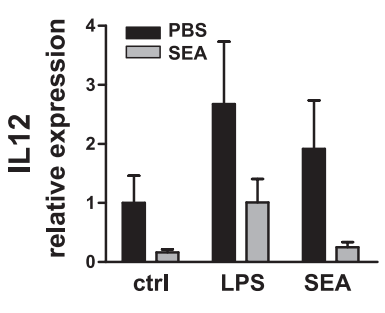

in vitro stimulus
$\mathbf{E}$

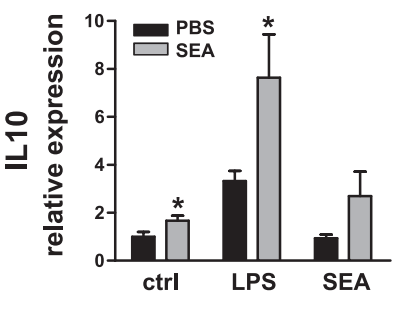

in vitro stimulus

$\mathbf{F}$

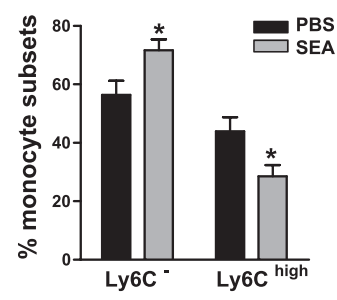

Figure 2. Short-term SEA treatment induces a $\mathrm{T}_{\mathrm{H}} 2$ response and anti-inflammatory macrophages in vivo. LDLR ${ }^{-/-}$mice fed an $\mathrm{HCD}$ were treated weekly with PBS or $50 \mu \mathrm{g}$ SEA s.c. for $5 \mathrm{wk}$. A) No differences were observed in circulating levels of T cells
after SEA treatment. B) SEA-treated $L D L R^{-/-}$mice show significant up-regulation of $\mathrm{T}_{\mathrm{H}} 2$ genes, while no difference in $\mathrm{T}_{\mathrm{H}} 1$ or $\mathrm{T}_{\text {reg }}$ gene expression was observed, as measured in splenocytes by qPCR. $C-E$ ) Peritoneal macrophages from SEA-treated $L D L R^{-/-}$mice show decreased expression of proinflammatory iNOS $(C)$ and IL-12 $(D)$ on 24 h LPS activation $e x$ vivo, while IL-10 gene expression $(E)$ was significantly upregulated in unstimulated and LPS-activated conditions ex vivo (measured by qPCR). F) SEA treatment diminished inflammatory Ly6 $\mathrm{C}^{\text {high }}$ blood monocytes while increasing the resident Ly6C ${ }^{-}$cells, as measured by flow cytometry. All bars represent means \pm SEM of 10 samples/group; ns, nonsignificant. $* P<0.05$, $* * P<0.01$.

markers in peritoneal macrophages from SEA-treated mice (Supplemental Fig. S1D-F). In agreement with an anti-inflammatory macrophage profile, SEA treatment significantly lowered the inflammatory status of the circulating monocyte pool, as the ratio of inflammatory Ly6C $^{\text {high }}$ vs. resident Ly6C $\mathrm{C}^{-}$monocytes was decreased compared with PBS-treated mice (Fig. 2F). Together, these data show that SEA treatment induces a shift in the inflammatory balance toward an anti-inflammatory profile of monocytes and macrophages.

\section{SEAs protect against atherosclerosis development}

To examine the effect of SEAs on atherosclerosis development, $L D L R^{-/-}$mice were placed on a HCD for $10 \mathrm{wk}$ while treated weekly with PBS or $50 \mu \mathrm{g}$ SEAs (long-term treatment). Again, SEA-treated mice did not display any health concerns or show any signs of abnormalities on pathological examination. Food intake (data not shown) and weight gain (Table 1) were comparable between PBS- and SEA-treated mice. Atherosclerotic plaque size was reduced by $44 \%$ in SEAtreated animals (Fig. 3A, B). Moreover, compared with PBS-injected mice, SEA-treated animals showed a strong reduction in lesion severity, as numbers of advanced lesions were diminished, while early and moderate plaques were significantly increased (Fig. $3 C)$.

\section{Atherosclerosis-protective effect of SEAs is mainly cholesterol independent}

As high plasma cholesterol levels are known to positively influence plaque development $(31,32)$, plasma lipid parameters were analyzed to elucidate potential mechanisms. Circulating triglyceride levels were unaffected by SEA treatment, and no differences in plasma cholesterol levels were observed between PBS and SEA-treated animals on chow diet (Table 1). However, after 5 and 10 wk of HCD, SEA-treated mice showed

TABLE 1. Weight and plasma cholesterol and triglyceride levels in PBS- vs. SEA-treated mice

\begin{tabular}{lccc}
\hline \hline Time HCD & Weight $(\mathrm{g})$ & Cholesterol $(\mathrm{mM})$ & Triglycerides $(\mathrm{mM})$ \\
\hline Before treatment & $19.61 \pm 0.30$ vs. $19.46 \pm 0.27$ & $6.27 \pm 0.15$ vs. $6.19 \pm 0.09$ & $1.20 \pm 0.08$ vs. $1.17 \pm 0.05$ \\
Before HCD & $20.00 \pm 0.28$ vs. $19.81 \pm 0.20$ & $6.66 \pm 0.18$ vs. $6.37 \pm 0.17$ & $1.24 \pm 0.08$ vs. $1.19 \pm 0.07$ \\
5 wk HCD & $21.24 \pm 0.28$ vs. $20.64 \pm 0.19$ & $39.31 \pm 1.31$ vs. $32.37 \pm 1.04 * * *$ & $3.33 \pm 0.22$ vs. $3.05 \pm 0.19$ \\
10 wk HCD & $21.71 \pm 0.34$ vs. $21.17 \pm 0.14$ & $45.17 \pm 1.36$ vs. $36.99 \pm 0.96 * * *$ & $3.10 \pm 0.19$ vs. $2.89 \pm 0.24$ \\
\hline
\end{tabular}

Comparisons are nonsignificant unless indicated. $* * * P<0.001$. 


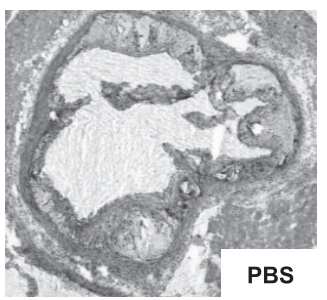

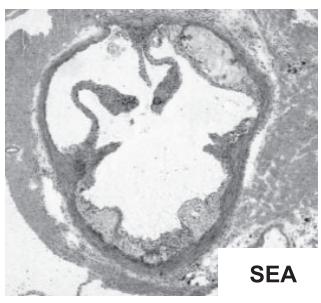

B

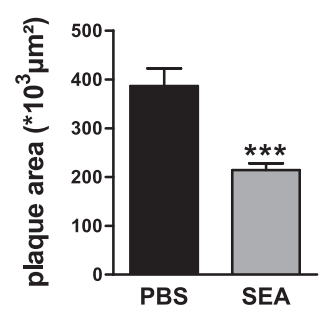

C

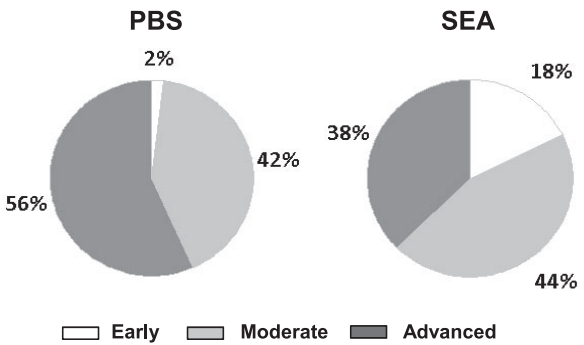

Figure 3. SEA treatment reduces atherosclerosis development. $L D L R^{-/-}$mice fed an HCD were treated weekly with PBS or 50 $\mu \mathrm{g}$ SEAs s.c. for $10 \mathrm{wk} . A, B)$ Plaque size was determined on cryosections of the aortic roots and found to be significantly reduced in SEA-treated mice, as determined by toluidin blue staining of the aortic root. A) Representative images. B) Quantification. Bars represent means \pm SEM of 20 animals/group. ${ }^{*} * *=0.0001$. C) Plaque progression was reduced after SEA treatment. Statistics $\chi^{2} P<0.001$.

significantly reduced plasma cholesterol levels (by 17.5 and $18.1 \%$ respectively; Table 1 ), mainly in the VLDLand LDL-sized particles (Fig. 4A). Subsequently, we tested whether the SEA-associated reduction in plasma cholesterol was the main determinant of the attenuated plaque formation by SEA treatment. After linear regression analyses of plasma cholesterol values in relation to plaque size, no difference could be observed regarding the slope of the curves, indicating an equal contribution of cholesterol in plaque development in both groups (Fig. 4B). Interestingly, the intercept of both curves was significantly different, indicating that at a certain cholesterol level, plaques from SEA-treated mice develop more slowly in comparison to plaques from PBS injected mice. To confirm this, animals from both groups with similar cholesterol exposure (range 35-45 mM) were selected, and plaque size was still significantly reduced (Fig. $4 C, D$ ) in SEA-treated animals, thereby supporting the conclusion that SEA treatment reduces atherosclerosis mainly independent of cholesterol.

\section{SEA treatment reduces systemic inflammation}

As atherosclerotic plaques are characterized and formed by the accumulation of inflammatory cells, circulating leukocytes were analyzed by flow cytometry. SEA treatment decreased total leukocyte numbers $\left(\mathrm{CD} 45^{+}\right.$cells $)$ by $24 \%$ (Fig. $\mathbf{5 A}$ ). No significant effects were seen on absolute numbers of circulating NK cells, B cells and T cells, and their subsets (Supplemental Fig. S2A-E). Surprisingly, in contrast to $5 \mathrm{wk}$ of SEA treatment (Fig. $2 B)$, long-term treatment did not show a clear T-cell polarization profile, as $\mathrm{T}_{\mathrm{H}} 1, \mathrm{~T}_{\mathrm{H}} 2$, and $\mathrm{T}_{\text {reg }}$ gene expression, as well as $T_{\text {reg }}$-cell numbers, were unaffected (Supplemental Fig. S2F, G). Interestingly, the reduction in total number of circulating leukocytes was mainly attributable to changes in cells of the myeloid lineage, as both circulating granulocytes (Fig. $5 B$ ) and monocytes (Fig. $5 C$ ) were significantly decreased. Regarding the latter, SEA treatment significantly diminished inflammatory Ly6 $\mathrm{C}^{\text {high }}$ monocytes both in blood (Fig. 4D, E) and spleen (Supplemental Fig, $\mathrm{S} 3 A)$. Decreased circulating monocytes and the Ly6C high subset was found to be independent of cholesterol lowering, as analyzed in mice from both groups with similar cholesterol exposure (Supplemental Fig S3B, C). Again, peritoneal macrophages from SEA-treated mice produced significantly more IL-10, as measured by intracellular flow cytometry (Fig. $4 F, G$ ) and at gene expression level (Supple-
A

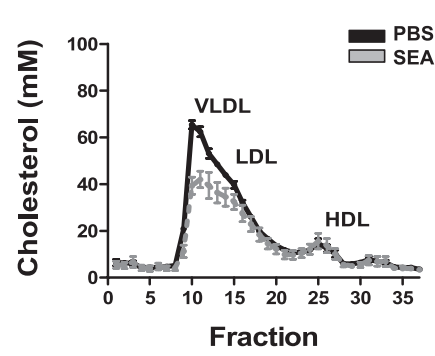

B

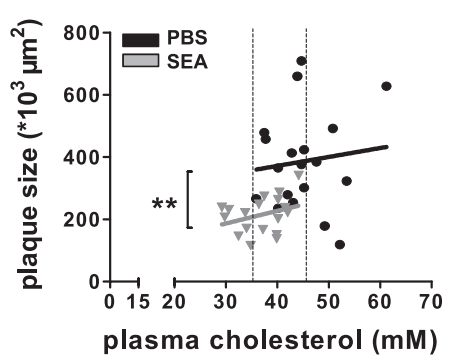

C

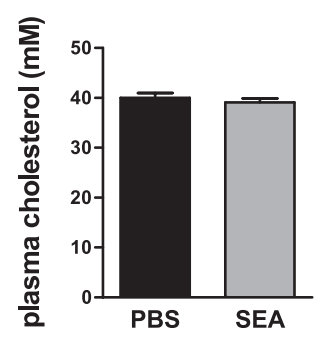

D

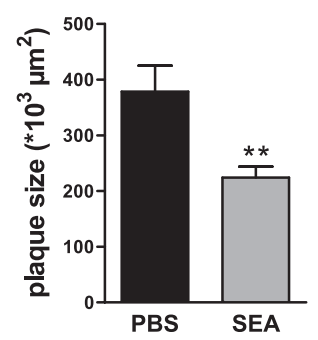

Figure 4. SEA treatment reduces atherosclerosis, independent of lowering plasma cholesterol. $L D L R^{-1-}$ mice fed an HCD were treated weekly with PBS or $50 \mu \mathrm{g}$ SEAs s.c. for $10 \mathrm{wk}$. A) Decreased cholesterol at wk 10 of HCD in SEA-treated mice is especially observed in VLDL and LDL fractions (measured in pooled plasma samples, $n=3$ /group). $B$ ) Linear regression analyses of plasma cholesterol and plaque size showed a significant difference in intercept of regression lines. Bars represent means \pm SEM of 20 animals/group. $P=0.007$. $C, D$ ) After selecting mice with similar cholesterol exposure (range $35-45 \mathrm{mM}$; $C$ ) in both the PBS- and SEA-treated groups, plaque size $(D)$ was still significantly reduced in SEA- vs. PBS-treated mice. Bars represent means \pm SEM of 8 animals/group. $* * P<0.01$. 
A

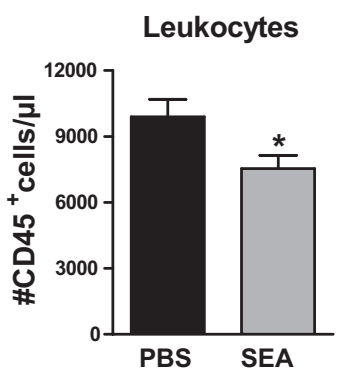

D

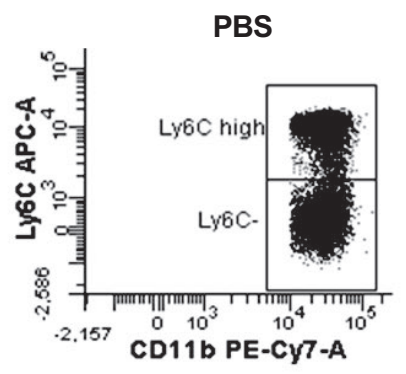

F

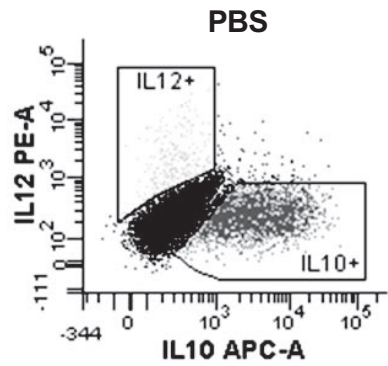

B

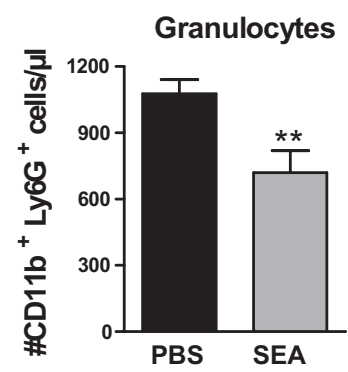

SEA

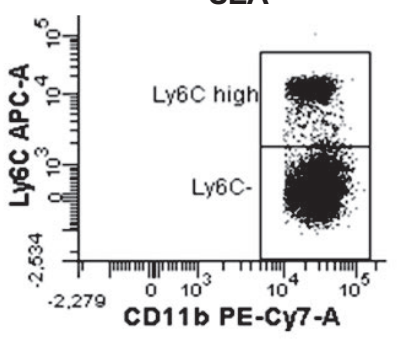

SEA

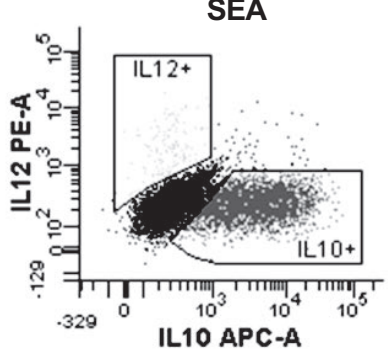

C

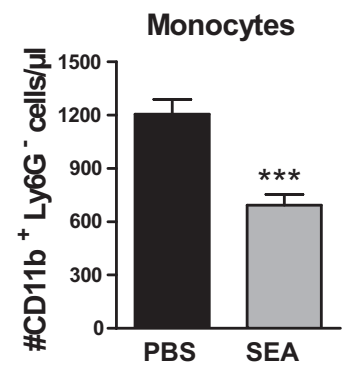

E

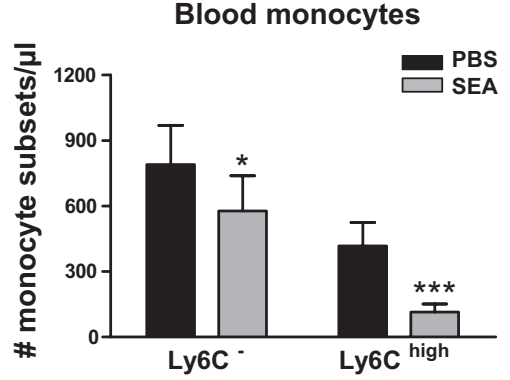

G

Peritoneal $\mathrm{m} \phi$

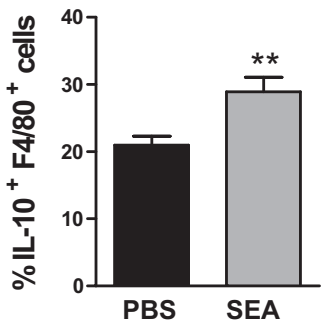

Figure 5. SEA treatment reduces systemic inflammation, predominantly at the myeloid level. $L D L R^{-/-}$mice fed an HCD were treated weekly with PBS or $50 \mu \mathrm{g}$ SEAs s.c. for $10 \mathrm{wk} . A-C)$ Total leukocyte numbers $(A)$ were decreased after SEA treatment, which was attributed to reduced granulocyte $(B)$ and monocyte $(C)$ counts. $D$, E) SEA treatment diminished circulating inflammatory Ly6C $\mathrm{C}^{-}$and Ly6C ${ }^{\text {high }}$ monocytes. $\left.F, G\right)$ Peritoneal macrophages from SEA-treated mice produced more IL-10. Bars represent means \pm SEM of 10 animals/group. All samples were measured by flow cytometry. $* P<0.05, * * P<0.01, * * * P<$ 0.0001 .

mental Fig. S3D), while LPS-induced TNF- $\alpha$ gene expression was decreased (Supplemental Fig. S3E). Together, these data show that SEAs reduce circulating numbers as well as the inflammatory status of myeloid cells systemically.

\section{Intraplaque inflammation is reduced by SEA treatment}

Next, we assessed whether the systemic immune modulation was also reflected in the atherosclerotic plaques. By pathological examination, we found plaques from SEA-treated mice to feature decreased plaque necrosis, less activated endothelium, and attenuated adventitial inflammation (Supplemental Fig. S4). Moreover, in line with the observed systemic effects, plaques from SEA-treated mice featured less small inflammatory macrophages, granulocytes, and reduced monocyte adhesion. On detailed quantifica- tion, necrotic core and neutrophil content (NIMP1 ${ }^{+}$ cells) were found to be decreased by SEA treatment by 46 and $45 \%$, respectively (Fig. $6 \boldsymbol{B}, \boldsymbol{C}$ ). Moreover, newly recruited myeloid cells in the plaques, as analyzed by ERMP-58 staining (33), were reduced by $39 \%$ in SEA-treated mice (Fig. 6D), and gene expression in the aortic root showed significantly decreased CD68 expression (Fig. 7A), both indicative of reduced accumulation of macrophages on SEA treatment. Furthermore, TNF- $\alpha$ expression (Fig. $7 B$ ) was downregulated in arches from SEA-treated mice, as were ICAM-1, VCAM-1, and MCP-1 mRNA expression (Fig. $7 C-E$ ).

As these data point toward reduced monocyte adhesion in lesions after SEA treatment, adhesion of macrophages to endothelial cells was studied in vitro. Interestingly, SEA-treated macrophages showed less adherence to activated endothelium compared with controls (Fig. $7 F, G$ ). 
A
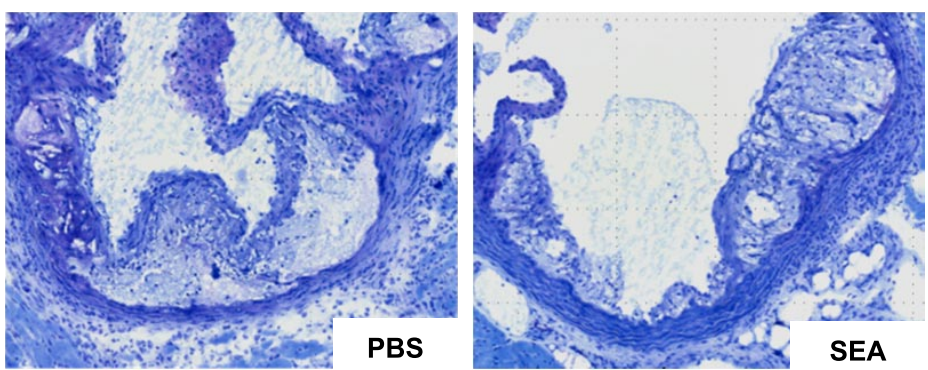

C
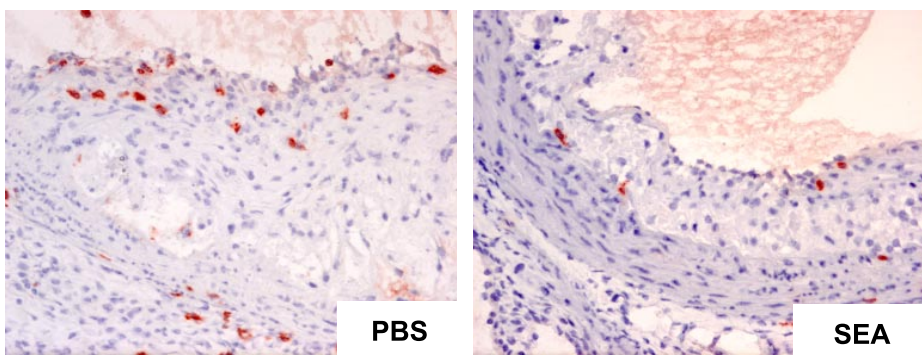

E

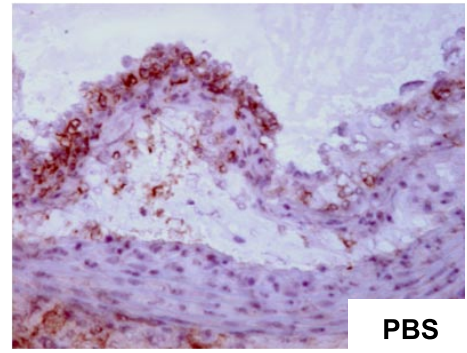

B

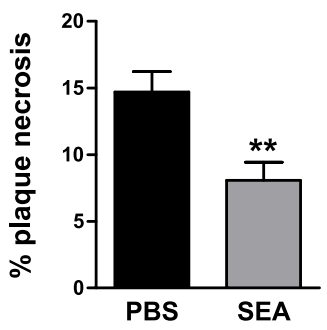

D
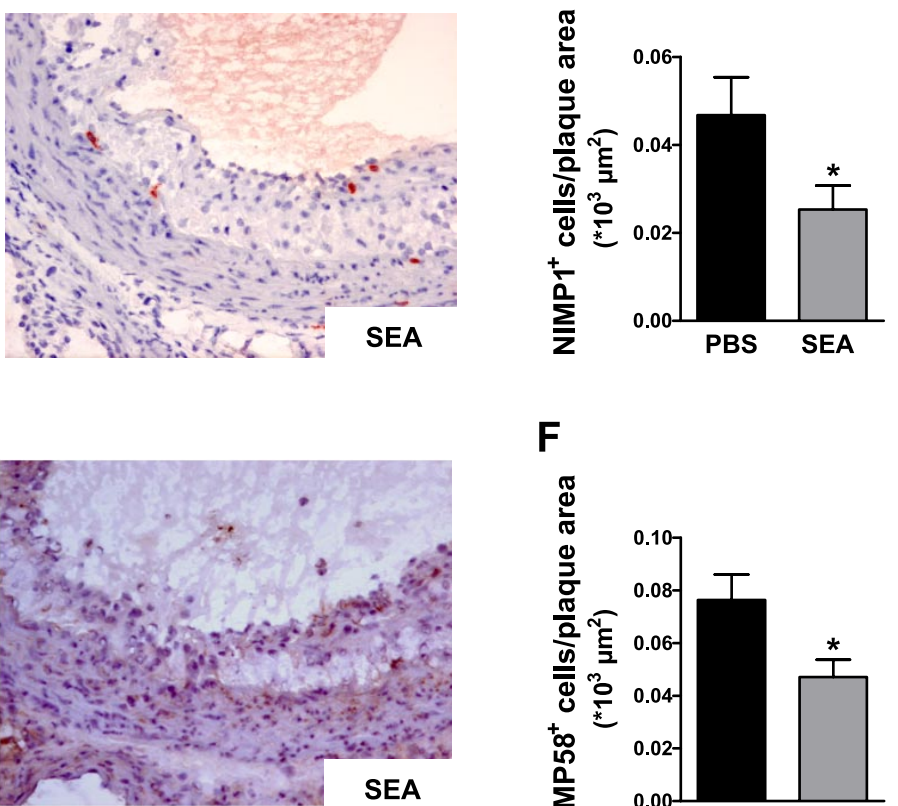

$\mathbf{F}$

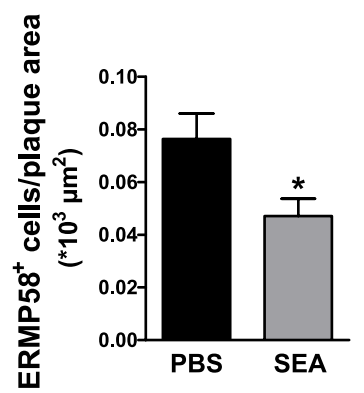

Figure 6. Intraplaque inflammation is decreased after SEA treatment. $A, B$ ) SEA treatment reduced plaque necrosis, as determined on toluidin blue section of the aortic roots. $C, D$ ) Lesions from SEA-treated mice showed less plaque neutrophils, as determined by NIMP1 staining. $E, F$ ) Plaques from SEA-treated mice showed less recruitment of myeloid cells, as determined by ERMP58 staining. Bars represent means \pm SEM of 20 animals/group. All were measured by immunohistochemistry. $* P<0.05$, $* * P<0.01$.

\section{DISCUSSION}

In this study, we show that treatment with S. mansoni SEAs highly protects against cholesterol-induced atherosclerosis development. Our results show that besides lowering plasma cholesterol levels, SEAs mainly act atheroprotective by alleviating the hyperlipidemia-induced proinflammatory status, as we found SEAs to decrease total circulating leukocytes, predominantly granulocytes and monocytes, and to skew these cells toward an anti-inflammatory phenotype. In line with this finding, atherosclerotic lesions of SEA-treated animals showed a strongly decreased inflammatory plaque burden.

Schistosomes and schistosome-derived antigens are known strong immune modulators (34). Schistosome eggs and their soluble products induce an intense $\mathrm{T}_{\mathrm{H}} 2$ bias in their host (35), and macrophages are polarized toward alternatively activated M2a macrophages (34). Moreover, helminth antigens have been shown to in- hibit proper maturation and activation of DCs, which augments $\mathrm{T}_{\mathrm{H}} 2$ responses both in vivo and in vitro (36). During chronic helminth infection, $\mathrm{T}_{\text {reg }}$ cells are induced and high levels of IL-10 are secreted by cells of both the innate and adaptive immune system, which suppress further immune responses (34). As a consequence of these immune-modulating effects, infection with helminths and the administration of their antigens have been shown to counteract inflammatory responses and improve the outcome of chronic inflammatory diseases, such as colitis (16), multiple sclerosis (14), type I diabetes (15), etc. Interestingly, immune dampening by helminths and their products via $\mathrm{T}_{\text {reg }}$ and IL-10 induction has also been shown to suppress immune reactivity to nonhelminth antigens, such as allergens or self-antigens (34). Thus, these findings postulate valuable applications of helminths and their antigens in the prevention of autoimmune and chronic inflammatory diseases. 


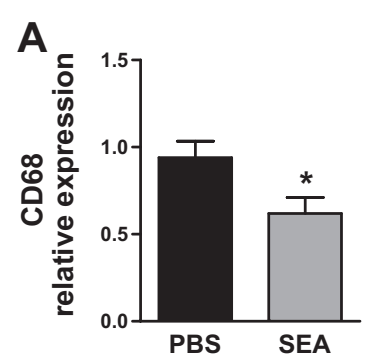

D
B

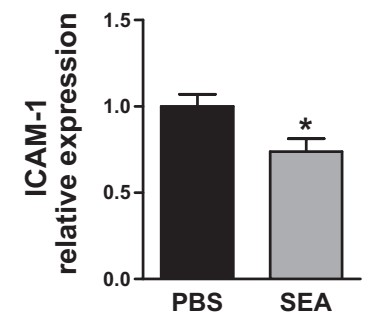

SEA

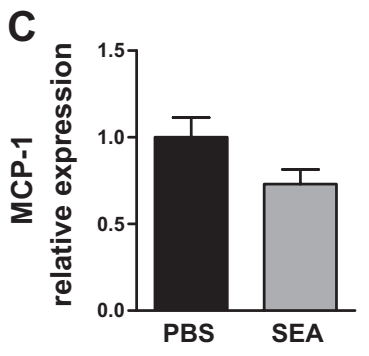

$\mathbf{E}$
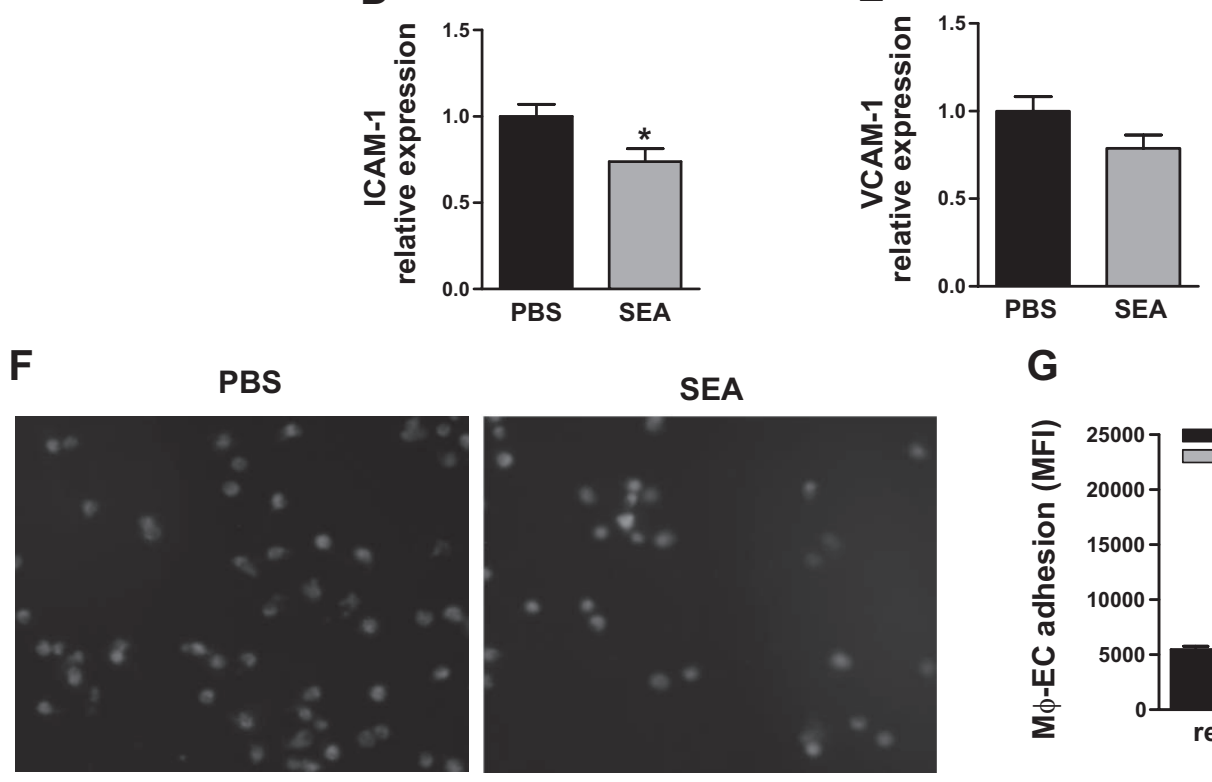

G

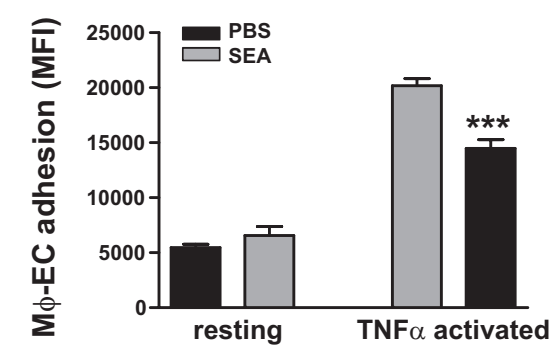

Figure 7. SEA treatment decreases inflammatory plaque burden and reduces monocyte adhesion to activated endothelium. $A-E$ ) Gene expression analysis of aortic arches showed diminished expression of CD68, TNF- $\alpha$, ICAM-1, VCAM-1, and MCP-1 in SEA- vs. PBS-treated mice. Bars represent means \pm SEM of 20 animals/group. $F, G$ ) SEA-treated macrophages were less adhering to TNF- $\alpha$-activated endothelial cells in vitro. $F$ ) Representative images of the adhesion assay. $G$ ) Calculated mean fluorescent intensity (MFI). Bars represent means \pm SEM of 5 samples/condition. $* P<0.05, * * * P<0.001$.

Regarding cardiovascular diseases, Assaad-khalil et al. (37) were the first to report reduced incidence of atherosclerosis in patients with schistosomal infections. Later, Doenhoff et al. (38) showed that murine plaque formation was diminished by $50 \%$ after $S$. mansoni worm infection, and this was mainly attributed to reduced blood cholesterol levels. In contrast, La Flamme et al. (39) could not find reduced plaque size after chronic S. mansoni egg exposure in $A p o E^{-1-}$ mice fed a western-type diet, although they also reported reduced plasma cholesterol concentrations. Potentially, the use of dead schistosome eggs in the latter study could explain the observed differences between the studies, and the researchers suggested that the protective effects on atherosclerosis cannot be replicated without exposure to live helminths (39). However, in this study, we are the first to show that treatment with helminth-derived antigens itself leads to a great reduction in plaque size and progression in hypercholesterolemic $L D L R^{-/-}$without causing side effects. As high cholesterol levels are positively correlated with plaque growth, while reduction in plasma cholesterol values is related to plaque regression $(31,32)$, the reduced cholesterol levels we observe after SEA treatment may partly explain the diminished plaque size in our study. However, our data suggest that SEAs mainly protect against atherosclerosis development in a non-lipidrelated effect but instead by alleviating the proinflammatory systemic response, as mice with similar cholesterol exposure still showed a strong reduction in plaque size after SEA treatment. Moreover, foam cell formation was not affected by SEA priming (data not shown). Treating $L D L R^{-/-}$mice with SEAs strongly reduced inflammatory Ly6C $\mathrm{C}^{\text {high }}$ monocytes, which are known to increase dramatically on high-fat feeding of mice (40, 41) and to be the key precursors to the majority of plaque macrophages (41). Coinciding with the reduced number of circulating inflammatory monocytes and granulocytes, SEA treatment abrogated recruitment and accumulation of myeloid cells in the plaques. In addition, plaques from SEA-injected mice showed reduced cellular adhesion to endothelial cells and dampened lesional expression of ICAM1, VCAM1, and MCP-1. We are the first to show that SEAs specifically target cells of the myeloid lineage and thereby have great beneficial effects on inflammatory mechanisms contributing to atherosclerosis development.

Another key finding in our study is the observed 
induction of anti-inflammatory macrophages after in vitro and in vivo SEA treatment, characterized by decreased production of proinflammatory mediators and high levels of IL-10. IL-10 is a known strong antiatherogenic cytokine, and overexpressing IL-10 through intramuscular gene transfer inhibited neointima formation by $45 \%$ in hypercholesterolemic APOE*3-Leiden mice (42). Interestingly, similar reductions in lesion size were observed after transplanting IL-10-overexpressing macrophages to hyperlipidemic $L D L R^{-1-}$ mice (43). Thus, increased IL-10 production by macrophages on SEA treatment may likely contribute to the strong atheroprotective properties of SEAs in our study.

Regarding changes in cytokine production in macrophages, similar observations were made in DCs, where SEAs decreased LPS-induced IL-12 and TNF- $\alpha$ while increasing IL-10 (24) in a TLR2-, MyD88-, and MAPKERK1/2-dependent manner $(20,44)$. Moreover, components of SEAs have been shown to activate NF- $\kappa B$ only transiently, in comparison to the persistent NF-kB activation by LPS (45). Relating to mostly DC and T-cell work, SEAs and derivatives have been shown to bind to a wide array of cell surface receptors, such as TLRs (TLR2, 3, and 4) and C-type lectins [DC-SIGN, MMR, macrophage galactose lectin 1 (MGL1), and galectin 1 and 3], and thereby to activate a multitude of intracellular pathways (13). The receptors and signaling pathways mediating the effect we observe in macrophages need to be further elucidated in the future.

In contrast to previous studies $(10,12,46)$, macrophages from SEA-treated mice did not show up-regulation of any markers of alternative M2a macrophage activation in our study, although a modest $\mathrm{T}_{\mathrm{H}} 2 \mathrm{~T}$ cell polarization was observed on short term SEA treatment. Instead, we found a general anti-inflammatory M2 macrophage phenotype on SEA treatment, characterized by high IL-10 production and diminished IL-12, $\mathrm{NO}$, and TNF- $\alpha$ secretion. Long-term SEA treatment resulted in a similar macrophage phenotype, while the $\mathrm{T}_{\mathrm{H}} 2$ response faded during chronic SEA injection. Diminished $\mathrm{T}_{\mathrm{H}} 2$ responses during chronic treatment are also seen during chronic life helminth infection (47). Together, these data imply that our observed macrophage profile is largely independent of T-lymphocyte responses. Possibly, the C57BL/6 background of the $L D L R^{-/-}$mice in our studies has dampened $\mathrm{T}_{\mathrm{H}} 2$ skewing, as most helminth studies are performed in $\mathrm{BALB} / \mathrm{c}$ mice, which are known to develop more robust $\mathrm{T}_{\mathrm{H}} 2$ T-cell skewing and M2a macrophage responses than C57BL/6 mice (48). In addition, the hyperlipidemic feeding of the $L D L R^{-/-}$mice potentially further dampens $\mathrm{T}_{\mathrm{H}} 2$ skewing, while pushing it more into a proinflammatory response. Regarding the strain diversity, Burton et al. (49) showed differential expression of SEA-binding recognition receptors on $\mathrm{T}$ cells of $\mathrm{BALB} / \mathrm{c}$ and C57BL/6 mice, thereby revealing dissimilarities in cellular binding and subsequent cellular responses in cells of different mouse strains. It is tempting to speculate that a similar strain-dependent difference exists in cells of the myeloid lineage, which could partly explain the
non-M2a macrophage phenotype observed in this study.

As SEAs are a complex mixture of both secretory and structural products of the helminth eggs (47), identifying and functionally characterizing components of this mixture may in the future contribute to novel and more specific inflammation-suppressing tools (22). The high glycosylation rate of SEA proteins, often with unique sugar combinations that are not found in mammals, is suggested to contribute to the immunomodulatory functions of SEAs (50). For example, the glycoprotein $\omega-1$ present in SEAs has been shown to elicit $\mathrm{T}_{\mathrm{H}} 2$ and $\mathrm{T}_{\text {reg }}$ responses comparable to those seen during worm infection $(51,52)$. Furthermore, the glycan lacto- $N$ fucopentaose III (LNFPIII) was found to induce $\mathrm{T}_{\mathrm{H}} 2$ responses (53) and alternatively activated macrophages in vivo (54) and to be protective against psoriasis (55) and EAE development (56). Interestingly, Bhargava et al. (57) recently reported the utility of LNFPIII in targeting metabolic syndrome-related pathologies, as obese mice treated with LNFPIII showed improved insulin sensitivity, decreased inflammation in white adipose tissue, and suppressed lipogenesis in the liver. Also here, a strong induction of IL-10-producing macrophages and DCs was observed, which was suggested to play important functions in reducing adipose tissue inflammation and sensitizing the insulin response of adipocytes.

Taken together, our results show that systemic reprogramming of monocytes and macrophages to an antiinflammatory profile strongly reduces atherosclerotic plaque development. Future research should focus on identifying the specific antiatherosclerotic components of SEAs and other helminth-derived products with similar immune modulatory capacities to open the gate for the development of novel therapeutic tools to treat chronic inflammatory diseases like atherosclerosis. F F

M.M.P.C.D. and M.P.J.D.W. are supported by The Netherlands Heart Foundation (Dr. E. Dekker postdoctoral fellow grants 2007T034 and 2012 T079 to M.M.P.C.D.; Dr. E. Dekker investigator grant 2007T067 to M.P.J.D.W.) and Nederlandse Organisatie voor Wetenschappelijk Onderz (NWO)-Vidi grant 917.066.329 (to M.P.J.D.W.). The funders had no role in study design, data collection and analysis, decision to publish, or preparation of the manuscript. The authors declare no conflicts of interest.

\section{REFERENCES}

1. Hansson, G. K., and Hermansson, A. (2011) The immune system in atherosclerosis. Nat. Immunol. 12, 204-212

2. Sica, A., and Mantovani, A. (2012) Macrophage plasticity and polarization: in vivo veritas. J. Clin. Invest. 122, 787-795

3. Martinez, F. O., Sica, A., Mantovani, A., and Locati, M. (2008) Macrophage activation and polarization. Front. Biosci. 13, 453461

4. Bouhlel, M. A., Staels, B., and Chinetti-Gbaguidi, G. (2008) Peroxisome proliferator-activated receptors-from active regulators of macrophage biology to pharmacological targets in the treatment of cardiovascular disease. J. Intern. Med. 263, 28-42

5. Boyle, J. J. (2005) Macrophage activation in atherosclerosis: pathogenesis and pharmacology of plaque rupture. Curr. Vasc. Pharmacol. 3, 63-68 
6. Khallou-Laschet, J., Varthaman, A., Fornasa, G., Compain, C., Gaston, A. T., Clement, M., Dussiot, M., Levillain, O., GraffDubois, S., Nicoletti, A., and Caligiuri, G. (2010) Macrophage plasticity in experimental atherosclerosis. PLoS One 5, e8852

7. Stoger, J. L., Gijbels, M. J., van der Velden, S., Manca, M., van der Loos, C. M., Biessen, E. A., Daemen, M. J., Lutgens, E., and de Winther, M. P. (2012) Distribution of macrophage polarization markers in human atherosclerosis. Atherosclerosis 225, 461468

8. Van der Valk, F. M., van Wijk, D. F., and Stroes, E. S. (2012) Novel anti-inflammatory strategies in atherosclerosis. Curr. Opin. Lipidol. 23, 532-539

9. Weinstock, J. V. (2012) Autoimmunity: the worm returns. Nature 491, 183-185

10. Maizels, R. M., and Yazdanbakhsh, M. (2003) Immune regulation by helminth parasites: cellular and molecular mechanisms. Nat. Rev. Immunol. 3, 733-744

11. Herbert, D. R., Holscher, C., Mohrs, M., Arendse, B., Schwegmann, A., Radwanska, M., Leeto, M., Kirsch, R., Hall, P., Mossmann, H., Claussen, B., Forster, I., and Brombacher, F. (2004) Alternative macrophage activation is essential for survival during schistosomiasis and downmodulates $\mathrm{T}$ helper 1 responses and immunopathology. Immunity 20, 623-635

12. Kreider, T., Anthony, R. M., Urban, J. F., Jr., and Gause, W. C. (2007) Alternatively activated macrophages in helminth infections. Curr. Opin. Immunol. 19, 448-453

13. Harnett, W., and Harnett, M. M. (2010) Helminth-derived immunomodulators: can understanding the worm produce the pill? Nat. Rev. Immunol. 10, 278-284

14. Sewell, D., Qing, Z., Reinke, E., Elliot, D., Weinstock, J., Sandor, M., and Fabry, Z. (2003) Immunomodulation of experimental autoimmune encephalomyelitis by helminth ova immunization. Int. Immunol. 15, 59-69

15. Cooke, A., Tonks, P., Jones, F. M., O'Shea, H., Hutchings, P., Fulford, A. J., and Dunne, D. W. (1999) Infection with Schistosoma mansoni prevents insulin dependent diabetes mellitus in non-obese diabetic mice. Parasite Immunol. 21, 169-176

16. Smith, P., Mangan, N. E., Walsh, C. M., Fallon, R. E., McKenzie, A. N., van Rooijen, N., and Fallon, P. G. (2007) Infection with a helminth parasite prevents experimental colitis via a macrophage-mediated mechanism. J. Immunol. 178, 4557-4566

17. Summers, R. W., Elliott, D. E., Urban, J. F., Jr., Thompson, R., and Weinstock, J. V. (2005) Trichuris suis therapy in Crohn's disease. Gut 54, 87-90

18. Summers, R. W., Elliott, D. E., Urban, J. F., Jr., Thompson, R. A., and Weinstock, J. V. (2005) Trichuris suis therapy for active ulcerative colitis: a randomized controlled trial. Gastroenterology 128, 825-832

19. Summers, R. W., Elliott, D. E., and Weinstock, J. V. (2005) Why Trichuris suis should prove safe for use in inflammatory bowel diseases. Inflamm. Bowel Dis. 11, 783-784

20. Correale, J., and Farez, M. (2009) Helminth antigens modulate immune responses in cells from multiple sclerosis patients through TLR2-dependent mechanisms. J. Immunol. 183, 59996012

21. Fleming, J. O., Isaak, A., Lee, J. E., Luzzio, C. C., Carrithers, M. D., Cook, T. D., Field, A. S., Boland, J., and Fabry, Z. (2011) Probiotic helminth administration in relapsing-remitting multiple sclerosis: a phase 1 study. Mult. Scler. 17, 743-754

22. Kuijk, L. M., and van Die, I. (2010) Worms to the rescue: can worm glycans protect from autoimmune diseases? IUBMB Life 62, 303-312

23. Zheng, X., Hu, X., Zhou, G., Lu, Z., Qiu, W., Bao, J., and Dai, Y. (2008) Soluble egg antigen from Schistosoma japonicum modulates the progression of chronic progressive experimental autoimmune encephalomyelitis via Th2-shift response. J. Neuroimmunol. 194, 107-114

24. Zaccone, P., Fehervari, Z., Jones, F. M., Sidobre, S., Kronenberg, M., Dunne, D. W., and Cooke, A. (2003) Schistosoma mansoni antigens modulate the activity of the innate immune response and prevent onset of type 1 diabetes. Eur. J. Immunol. 33, $1439-1449$

25. Grzych, J. M., Pearce, E., Cheever, A., Caulada, Z. A., Caspar, P., Heiny, S., Lewis, F., and Sher, A. (1991) Egg deposition is the major stimulus for the production of Th2 cytokines in murine schistosomiasis mansoni. J. Immunol. 146, 1322-1327
26. Boros, D. L., and Warren, K. S. (1970) Delayed hypersensitivitytype granuloma formation and dermal reaction induced and elicited by a soluble factor isolated from Schistosoma mansoni eggs. J. Exp. Med. 132, 488-507

27. Nagayama, Y., Watanabe, K., Niwa, M., McLachlan, S. M., and Rapoport, B. (2004) Schistosoma mansoni and alpha-galactosylceramide: prophylactic effect of Th1 Immune suppression in a mouse model of Graves' hyperthyroidism. J. Immunol. 173, 2167-2173

28. Pancre, V., Delacre, M., Herno, J., and Auriault, C. (1999) Schistosomal egg antigen-responsive CD8 T-cell population in Schistosoma mansoni-infected BALB/c mice. Immunology 98, 525534

29. Goossens, P., Gijbels, M. J., Zernecke, A., Eijgelaar, W., Vergouwe, M. N., van der Made, I., Vanderlocht, J., Beckers, L., Buurman, W. A., Daemen, M. J., Kalinke, U., Weber, C., Lutgens, E., and de Winther, M. P. (2010) Myeloid type I interferon signaling promotes atherosclerosis by stimulating macrophage recruitment to lesions. Cell Metab. 12, 142-153

30. Pearce, E. J., Cheever, A., Leonard, S., Covalesky, M., FernandezBotran, R., Kohler, G., and Kopf, M. (1996) Schistosoma mansoni in IL-4-deficient mice. Int. Immunol. 8, 435-444

31. Feig, J. E., Parathath, S., Rong, J. X., Mick, S. L., Vengrenyuk, Y., Grauer, L., Young, S. G., and Fisher, E. A. (2011) Reversal of hyperlipidemia with a genetic switch favorably affects the content and inflammatory state of macrophages in atherosclerotic plaques. Circulation 123, 989-998

32. Potteaux, S., Gautier, E. L., Hutchison, S. B., van Rooijen, N., Rader, D. J., Thomas, M. J., Sorci-Thomas, M. G., and Randolph, G. J. (2011) Suppressed monocyte recruitment drives macrophage removal from atherosclerotic plaques of Apoe-/ - mice during disease regression. J. Clin. Invest. 121, 2025-2036

33. Goossens, P., Vergouwe, M. N., Gijbels, M. J., Curfs, D. M., van Woezik, J. H., Hoeksema, M. A., Xanthoulea, S., Leenen, P. J., Rupec, R. A., Hofker, M. H., and de Winther, M. P. (2011) Myeloid IkappaBalpha deficiency promotes atherogenesis by enhancing leukocyte recruitment to the plaques. PLoS One 6, e22327

34. Dunne, D. W., and Cooke, A. (2005) A worm's eye view of the immune system: consequences for evolution of human autoimmune disease. Nat. Rev. Immunol. 5, 420-426

35. Pearce, E. J., Caspar, P., Grzych, J. M., Lewis, F. A., and Sher, A. (1991) Downregulation of Thl cytokine production accompanies induction of Th2 responses by a parasitic helminth, Schistosoma mansoni. J. Exp. Med. 173, 159-166

36. Pearce, E. J., and MacDonald, A. S. (2002) The immunobiology of schistosomiasis. Nat. Rev. Immunol. 2, 499-511

37. Assaad-Khalil, S. H., Lachine, N., Sidrak, M., Amara, F., Jacotot, B., and Fahmy, M. H. (1992) Immuno-metabolic factors in schistosomal hepatic fibrosis modulating atherogenesis. Ann. Biol. Clin. (Paris) 50, 697-701

38. Doenhoff, M. J., Stanley, R. G., Griffiths, K., and Jackson, C. L. (2002) An anti-atherogenic effect of Schistosoma mansoni infections in mice associated with a parasite-induced lowering of blood total cholesterol. Parasitology 125, 415-421

39. La Flamme, A. C., Harvie, M., Kenwright, D., Cameron, K., Rawlence, N., Low, Y. S., and McKenzie, S. (2007) Chronic exposure to schistosome eggs reduces serum cholesterol but has no effect on atherosclerotic lesion development. Parasite Immunol. 29, 259-266

40. Swirski, F. K., Libby, P., Aikawa, E., Alcaide, P., Luscinskas, F. W., Weissleder, R., and Pittet, M. J. (2007) Ly-6Chi monocytes dominate hypercholesterolemia-associated monocytosis and give rise to macrophages in atheromata. J. Clin. Invest. 117, 195-205

41. Tacke, F., Alvarez, D., Kaplan, T. J., Jakubzick, C., Spanbroek, R., Llodra, J., Garin, A., Liu, J., Mack, M., van Rooijen, N., Lira, S. A., Habenicht, A. J., and Randolph, G. J. (2007) Monocyte subsets differentially employ CCR2, CCR5, and CX3CR1 to accumulate within atherosclerotic plaques. J. Clin. Invest. 117, 185-194

42. Eefting, D., Schepers, A., De Vries, M. R., Pires, N. M., Grimbergen, J. M., Lagerweij, T., Nagelkerken, L. M., Monraats, P. S., Jukema, J. W., van Bockel, J. H., and Quax, P. H. (2007) The effect of interleukin-10 knock-out and overexpression on neointima formation in hypercholesterolemic APOE*3-Leiden mice. Atherosclerosis 193, 335-342 
43. Han, X., Kitamoto, S., Wang, H., and Boisvert, W. A. (2010) Interleukin-10 overexpression in macrophages suppresses atherosclerosis in hyperlipidemic mice. FASEB J. 24, 2869-2880

44. Goh, F., Irvine, K. M., Lovelace, E., Donnelly, S., Jones, M. K., Brion, K., Hume, D. A., Kotze, A. C., Dalton, J. P., Ingham, A., and Sweet, M. J. (2009) Selective induction of the Notch ligand Jagged-1 in macrophages by soluble egg antigen from Schistosoma mansoni involves ERK signalling. Immunology 127, 326-337

45. Thomas, P. G., Carter, M. R., Da'dara, A. A., DeSimone, T. M., and Harn, D. A. (2005) A helminth glycan induces APC maturation via alternative NF-kappa B activation independent of I kappa B alpha degradation. J. Immunol. 175, 2082-2090

46. Zaccone, P., Burton, O. T., Gibbs, S., Miller, N., Jones, F. M., Dunne, D. W., and Cooke, A. Immune modulation by Schistosoma mansoni antigens in NOD mice: effects on both innate and adaptive immune systems. J. Biomed. Biotechnol. 2010:795210, 2010

47. Schramm, G., and Haas, H. (2010) Th2 immune response against Schistosoma mansoni infection. Microbes Infect. 12, 881-888

48. Zaccone, P., Burton, O., Miller, N., Jones, F. M., Dunne, D. W., and Cooke, A. (2009) Schistosoma mansoni egg antigens induce Treg that participate in diabetes prevention in NOD mice. Eur. J. Immunol. 39, 1098-1107

49. Burton, O. T., Gibbs, S., Miller, N., Jones, F. M., Wen, L., Dunne, D. W., Cooke, A., and Zaccone, P. (2010) Importance of TLR2 in the direct response of T lymphocytes to Schistosoma mansoni antigens. Eur. J. Immunol. 40, 2221-2229

50. Van Die, I., and Cummings, R. D. (2010) Glycan gimmickry by parasitic helminths: a strategy for modulating the host immune response? Glycobiology 20, 2-12

51. Zaccone, P., Burton, O. T., Gibbs, S. E., Miller, N., Jones, F. M., Schramm, G., Haas, H., Doenhoff, M. J., Dunne, D. W., and
Cooke, A. (2011) The S. mansoni glycoprotein omega-1 induces Foxp3 expression in NOD mouse CD4(+) T cells. Eur. J. Immunol. 41, 2709-2718

52. Everts, B., Perona-Wright, G., Smits, H. H., Hokke, C. H., van der Ham, A. J., Fitzsimmons, C. M., Doenhoff, M. J., van der Bosch, J., Mohrs, K., Haas, H., Mohrs, M., Yazdanbakhsh, M., and Schramm, G. (2009) Omega-1, a glycoprotein secreted by Schistosoma mansoni eggs, drives Th2 responses. J. Exp. Med. 206, 1673-1680

53. Okano, M., Satoskar, A. R., Nishizaki, K., and Harn, D. A., Jr. (2001) Lacto-N-fucopentaose III found on Schistosoma mansoni egg antigens functions as adjuvant for proteins by inducing Th2-type response. J. Immunol. 167, 442-450

54. Atochina, O., Da'dara, A. A., Walker, M., and Harn, D. A. (2008) The immunomodulatory glycan LNFPIII initiates alternative activation of murine macrophages in vivo. Immunology 125, 111-121

55. Atochina, O., and Harn, D. (2006) Prevention of psoriasis-like lesions development in fsn/fsn mice by helminth glycans. Exp. Dermatol. 15, 461-468

56. Fu, G. X., Xu, C. C., Zhong, Y., Zhu, D. L., and Gao, P. J. (2012) Aldosterone-induced osteopontin expression in vascular smooth muscle cells involves MR, ERK, and p38 MAPK. Endocrine 42, 676-683

57. Bhargava, P., Li, C., Stanya, K. J., Jacobi, D., Dai, L., Liu, S., Gangl, M. R., Harn, D. A., and Lee, C. H. (2012) Immunomodulatory glycan LNFPIII alleviates hepatosteatosis and insulin resistance through direct and indirect control of metabolic pathways. Nat. Med. 18, 1665-1672

Received for publication June 17, 2013. Accepted for publication September 3, 2013. 